\title{
Does immunoglobulin therapy have a role in treating Dengue virus infection with induced systemic capillary leak syndrome?
}

\author{
Sujoy Khan* \\ Department of Allergy \& Immunology, Apollo Gleneagles Hospital, West Bengal, India
}

Received 1 October 2012

Accepted 2 October 2012

\section{Dear Editor,}

The report of severe cardiovascular changes in the eight children with secondary dengue infection and dengue shock syndrome (DSS) by Kositseth et al. [1] was consistent with systemic capillary leak syndrome (SCLS). It is thought to be distinct from classical dengue fever (DF). However, clinicians working in endemic areas need to be aware that such textbook presentations may not be applicable in this age when extremes of climate and increase in air travel have complicated the infection demographics in clinical medicine. A report published in March 2012, showed the high prevalence of SCLS among travelers, a third of which were primary dengue cases and $85 \%$ also had classical DF [2]. It is interesting to hypothesize that patients co-infected with two serotypes of dengue virus (DENV) may develop multiple organ failure and DSS, but no specific reports on these complications are available from Asia (DENV-2/-3 and DENV-3/-4), or the Americas (DENV-2/-3 and DENV-3/-4). Whether complications from multiple organ failure and DSS was the case in the recent epidemic of dengue virus related

\footnotetext{
*Address for correspondence: Sujoy Khan, Department of Allergy \& Immunology, Apollo Gleneagles Hospital, 58, Canal Circular Road, Kolkata - 700 054, West Bengal, India. Tel.: +91 (0) 332320 2040/ 2122; Fax: +91 (0) 332320 5218; E-mail: sujoykhan@ gmail.com.
}

deaths in children and adults from Eastern India during the rainy season/autumn 2012 remains to be proven [3].

As with most infectious pathogens, homologous DENV genetic recombination events have been widely reported [4,5], but fortunately, there have not been any reports of heterologous DENV-serotype recombination events. Such events would result in new chimeric strains and the immunological hypothesis of antibodyenhanced disease and multi-organ failure would be the most likely explanation [6]. Does high-dose intravenous immunoglobulin (hdIVIG) sourced from the local donor population, rather than imported, offer a viable treatment option in DENV-related SCLS? A publication from the European Registry of patients with idiopathic SCLS showed improvement after treatment with hdIVIG [7]. Treatment with hdIVIG certainly remains a feasible option with viral-related autoimmune manifestations such as Kawasaki disease, but will this treatment prove effective against the dreaded thrombocytopenia and SCLS in DENV infection? [8,9] Only a multi-center clinical trial can answer this question. In the interim time, civic and health authorities must work together with entomology and virology centers to prevent unnecessary deaths from this vector-borne disease.

\section{References}

[1] Khositseth A, Tangnararatchakit K, Chuansumrit A, Wanitkun S, Kuptanon T, Chaiyaratana W, et al. Cardiovascular change in 
children with dengue shock syndrome. J Pediatr Intensive Care 2012;1(3):153-60.

[2] Meltzer E, Heyman Z, Bin H, Schwartz E. Capillary leakage in travelers with dengue infection: implications for pathogenesis. Am J Trop Med Hyg 2012;86(3):536-9.

[3] Dengue diagnosis: a failure to learn. http://www.telegraphindia. com/archives/archive.html, Accessed, 26 September, 2012.

[4] Worobey M, Rambaut A, Holmes EC. Widespread intraserotype recombination in natural populations of dengue virus. Proc Natl Acad Sci U S A 1999;96(13):7352-7.

[5] Perez-Ramirez G, Diaz-Badillo A, Camacho-Nuez M, Cisneros A, Munoz Mde L. Multiple recombinants in two dengue virus, serotype-2 isolates from patients from Oaxaca, Mexico. BMC Microbiol 2009;9:260.
[6] Falconar AK, Martinez F. The NS1 glycoprotein can generate dramatic antibody-enhanced dengue viral replication in normal out-bred mice resulting in lethal multi-organ disease. PLoS One 2011;6(6):e21024.

[7] Gousseff M, Arnaud L, Lambert M, Hot A, Hamidou M, Duhaut P, et al. Capillary Leak Syndrome Registry. The systemic capillary leak syndrome: a case series of 28 patients from a European registry. Ann Intern Med 2011;154(7):464-71.

[8] Kharya G, Yadav SP, Katewa S, Sachdeva A. Management of severe refractory thrombocytopenia in dengue hemorrhagic fever with intravenous anti-D immune globulin. Pediatr Hematol Oncol 2011;28(8):727-32.

[9] Rajapakse S. Intravenous immunoglobulins in the treatment of dengue illness. Trans R Soc Trop Med Hyg 2009;103(9):867-70. 